\title{
Impact of an Evidence-Based Computerized Decision Support System on Primary Care Prescription Costs
}

\author{
S. Troy McMullin, PharmD ${ }^{1}$ \\ Thomas P. Lonergan, PharmD, MBA ${ }^{1}$ \\ Charles $S$. Rynearson, $R P h, M S^{2}$ \\ Thomas D. Doerr, $M D^{1}$ \\ Paul A. Veregge, MD, MS ${ }^{2}$ \\ Edward S. Scanlan, $M D^{2}$ \\ 'Department of Clinical Decision Support, \\ WELLINX, St. Louis, Mo \\ ${ }^{2}$ Affinity Health System, Menasha, Wis
}

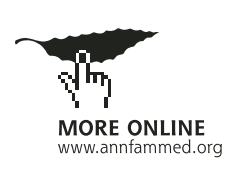

Conflicts of interest: Drs. McMullin and Lonergan are salaried employees of WELLINX. Dr. Doerr is one of the founders of WELLINX and has an ownership interest in the company.

\footnotetext{
CORRESPONDING AUTHOR

S. Troy McMullin, PharmD 10426 Baur Blvd

St. Louis, MO 63132

tmcmullin@wellinx.com
}

\begin{abstract}
PURPOSE Although newer, heavily promoted medications are commonly prescribed, published evidence and consensus guidelines often support the use of less expensive alternatives. This study was designed to evaluate the impact on prescription costs of a computerized decision support system (CDSS) that provides evidence-based recommendations to clinicians during the electronic prescribing process.
\end{abstract}

METHODS A retrospective cohort study was performed using a pharmacy claims database. Clinicians using the CDSS were matched with a control group by pharmacy billed amount, number of patients treated, and number of new prescriptions filled during a 6-month baseline period in which neither group used the system. The primary outcome measure was the difference in prescription costs between the 2 groups after implementation of the CDSS in the intervention group.

RESULTS Clinicians who received evidence-based messages had significantly lower prescription costs than those in the control group. The average cost per new prescription was $\$ 4.16$ lower $(P=.02)$ in the intervention group, and the average cost for new and refilled prescriptions was $\$ 4.99$ lower $(P=.01)$. The 6 -month savings from new prescriptions and their refills are estimated to be $\$ 3,450$ (95\% $\mathrm{Cl}, \$ 1,030-\$ 5,863)$ per clinician.

CONCLUSIONS Providing electronic, evidence-based decision support during the prescribing process can shift prescribing decisions toward more evidence-based care and significantly decrease primary care prescription costs.

Ann Fam Med 2004;2:494-498. DOI: 10.1370/afm.233.

\section{INTRODUCTION}

$\mathrm{F}$ or some physicians, representatives from pharmaceutical companies have become the most frequently used source of new medical information. In a study of 108 primary care physicians, information about the last new drug prescribed was derived more often from pharmaceutical company representatives than from the primary literature (42\% vs $9 \%$, respectively). ${ }^{1}$ Unfortunately, reliance on promotional information from pharmaceutical representatives has been associated with higher rates of inappropriate prescribing, higher medication costs, and more frequent use of heavily promoted products. ${ }^{2-4}$

Computerized decision support systems (CDSSs) that provide unbiased, evidence-based information about the relative efficacy, safety, and cost of different therapeutic options might help physicians practice more fiscally responsible care. Two systematic reviews found that a CDSS could improve other aspects of physician performance, such as medical error rates, drug dosing, diagnosis, laboratory test usage, and adherence to clinical guidelines. ${ }^{5,6}$ Because most of these trials assessed internally developed, proprietary systems in hospital settings, there has been a call for research 
evaluating commercially available CDSSs and their impact in primary care. ${ }^{6,7}$

This study was designed to evaluate the impact of a commercially available CDSS on the cost of medications prescribed by primary care clinicians in a community-based, ambulatory setting. The CDSS provides diagnosis-specific, evidence-based messages during the electronic prescribing process. Most messages focus on the comparative efficacy, safety, and cost of different treatment options.

\section{METHODS}

\section{Description of the System}

The CDSS (WELLINX, St. Louis, Mo) delivers evidence-based decision support integrated into an electronic prescribing module. To enter a prescription, the clinician must first select a diagnosis. The CDSS then displays a list of prewritten prescriptions most appropriate for that condition, along with a brief, diagnosisspecific message (Figure 1, which is available online as supplemental data at http://www.annfammed. org/cgi/content/full/2/5/494/DC1). These messages automatically appear on a highlighted area above the list of prewritten prescriptions, but they do not require action by the clinician or directly interfere with the prescribing process in any way. All messages are hyperlinked to detailed evidence-based therapeutic reviews that contain supporting evidence from the primary literature and comparative cost information.

In addition to diagnosis-specific recommendations, the system provides evidence-based messages each day when clinicians log on to the system (Figure 2, online supplemental data at http://www.annfammed org/cgi/content/full/2/5/494/DC1). These

brief messages summarize important new studies, new safety warnings, and evidence-based treatment approaches. These messages automatically appear on the first screen that the clinician sees each morning.

\section{Design}

To assess the impact of the CDSS on prescription costs, we conducted a retrospective, cohort study using pharmacy claims data from Affinity Health System (Menasha, Wis). The Affinity Health System Institutional Review Board approved the study under the exempt category.

Affinity Health System includes a network of 17 primary care clinics, 3 hospitals, a freestanding surgery center, a long-term care facility, and the Network Health Plan. This plan has 80,000 members in health management organization and point-of-service products. Affinity Health System physicians receive no financial incentives related to pharmacy costs, and they are not involved in the development of any clinical content (ie, messages or therapeutic reviews) that is available in the CDSS.

The CDSS was implemented at Affinity Health System in several phases. The first group of clinicians began using the CDSS in May 2002, and others were added during the following months. Because new clinicians were being added to the system throughout the study period, the intervention group was limited to family practice and internal medicine clinicians who began using the CDSS before June 1, 2002. Although most users were physicians, nurse-practitioners and physicians' assistants were eligible for inclusion.

The intervention group was matched to a group of similar Affinity Health System clinicians who were not using the CDSS. Eligible control-group participants were identified using a database query of all new prescriptions filled by patients of family practice or internal medicine clinicians in the 6 months prior to implementation of the CDSS (November 2001 through April 2002). A new prescription was defined as a claim for a medication that the patient had not received in the previous 12 months. The study was limited to new prescriptions to minimize the impact of prescriptions that were refilled during the study period but written before the implementation of the system. The query was also limited to prescriptions written by the patient's primary care provider to exclude prescriptions written by specialists, clinicians providing coverage for the primary care clinician's patients, or others who would not have access to the CDSS.

The groups were matched on the pharmacy claim billed amount, number of patients treated, and number of new prescriptions filled in the 6-month baseline period. To further ensure that clinicians had similar prescribing behavior at baseline, the groups also were matched using data for 10 high-cost drug categories (Table 1). These 10 drug categories accounted for most of the new prescription expenditures.

Clinicians who did not provide care under the Network Health Plan for each of the 6 months before and after implementation were excluded from the matching process to avoid including clinicians with incomplete prescription data.

\section{Statistical Analysis}

The primary outcome measure was the difference in new prescription costs between groups during the 6-month postimplementation period. The groups' prescription costs were compared using the cost for the original prescription only and the cost for the original prescription plus all refills that were obtained within 6 months of the original prescription date. Secondary outcome measures included differences in costs for medications in the 10 high-cost drug categories. 


\begin{tabular}{|c|c|c|}
\hline Baseline Characteristics & $\begin{array}{l}\text { Intervention Group } \\
(\mathrm{n}=19) \\
\text { No. }\end{array}$ & $\begin{array}{c}\text { Control Group } \\
(\mathrm{n}=19) \\
\text { No. }\end{array}$ \\
\hline Member months & 91,542 & 92,094 \\
\hline $\begin{array}{l}\text { Number of patients treated with a new } \\
\text { prescription }\end{array}$ & 3,305 & 3,307 \\
\hline Number of new prescriptions & 5,920 & 5,920 \\
\hline Number of new and refilled prescriptions & 13,347 & 13,533 \\
\hline $\begin{array}{l}\text { Number of patients with a new prescription } \\
\text { from the high-cost drug categories }\end{array}$ & No. (\%) & No. (\%) \\
\hline Antibiotics & $923(28)$ & $954(29)$ \\
\hline Antidepressants & $369(11)$ & $367(11)$ \\
\hline Rhinitis medications & $334(10)$ & $346(11)$ \\
\hline GERD medications & $253(8)$ & $189(6)$ \\
\hline Asthma medications & $262(8)$ & $218(7)$ \\
\hline Diabetes medications & $154(5)$ & $177(5)$ \\
\hline Antihypertension medications, diuretics & $393(12)$ & $411(12)$ \\
\hline Lipid-lowering therapies & $150(5)$ & $204(6)$ \\
\hline Triptans and headache medications & $91(3)$ & $79(2)$ \\
\hline COX-2 inhibitors and NSAIDs & $385(12)$ & $277(8)$ \\
\hline Total & $2,496(76)$ & $2,434(74)$ \\
\hline \multicolumn{3}{|c|}{$\begin{array}{l}\text { GERD }=\text { gastroesophageal reflux disease, } \text { COX- } 2 \text { inhibitors = selective cyclooxygenase } 2 \text { inhibitors, NSAIDs = } \\
\text { nonsteroidal anti-inflammatory drugs. }\end{array}$} \\
\hline \multicolumn{3}{|c|}{$P>.1$ for all baseline comparisons, except GERD medications $(P=.04)$. } \\
\hline
\end{tabular}

Table 2. Primary Outcome Measures

\begin{tabular}{lcccc}
\hline & $\begin{array}{c}\text { Change } \\
\text { Paseline } \\
\text { Mean \$ (SE) }\end{array}$ & $\begin{array}{c}\text { Study Period } \\
\text { Mean \$ (SE) }\end{array}$ & $\begin{array}{c}\text { From } \\
\text { Baseline }\end{array}$ & $\begin{array}{c}\boldsymbol{P}^{*} \\
\text { Value }\end{array}$ \\
\hline $\begin{array}{l}\text { New prescriptions } \\
\text { Intervention group }\end{array}$ & $38.53(1.63)$ & $37.28(1.62)$ & -1.25 & .02 \\
$\quad$ Control group & $38.47(1.60)$ & $41.38(1.61)$ & $2.91^{\dagger}$ & \\
New and refilled prescriptions & & & & \\
$\quad$ Intervention group & $43.71(1.60)$ & $40.56(1.59)$ & $-3.15^{\dagger}$ & .01 \\
Control group & $44.06(1.59)$ & $45.90(1.59)$ & 1.84 & \\
\hline
\end{tabular}

Note: values are least squares mean (SE). $P>.1$ for all baseline comparisons.

* $P$ value for mixed model analysis (group-time interaction).

$+P<.05$ for comparison of baseline vs study period.

To account for patient clustering at the physician level, we analyzed differences between groups using a mixed model analysis of variance for continuous variables and generalized mixed linear model (using a logit link function and a binomially distributed error term) for dichotomous outcome variables. Outcomes were analyzed as a function of categorically defined study group (intervention vs control), time period (baseline vs study period), and their interaction (grouptime interaction). Marginal means and inferential tests of baseline differences and intervention effects were calculated in a manner that corrects standard errors and $P$ values for patient clustering. ${ }^{8}$ Two-tailed tests of significance were used and $P<.05$ was selected for the level of statistical significance. All analyses were performed using SAS/STAT Software Changes and Enhancements, release 8.2 (SAS Institute, Inc; Cary, NC, 2001).

\section{RESULTS}

Of the 50 clinicians who wrote prescriptions in the CDSS between June 1, 2002, and November 30, 2002, 19 were included in the intervention group. The other users were excluded because they did not start using the system until after the study period began (24), were not primary care clinicians (6), or did not provide patient care under the Network Health Plan for each of the 12 months (1).

As displayed in Table 1, the intervention and control groups were well matched at baseline. Each group consisted of 16 physicians, 2 nurse-practitioners, and 1 physician's assistant. During the 6-month baseline period, these clinicians accounted for a total of 183,636 member months, and 11,840 new prescriptions were written for 6,612 different patients. These new prescriptions generated an additional 15,040 refills within 6 months of the original prescription date. The total billed amount, number of patients treated, and number of prescriptions filled by patients in each group were nearly identical during the baseline period.

During the study period, the intervention and control groups continued to account for a similar number of member months $(92,558$ and 88,685 , respectively) and write a similar number of new prescriptions $(5,667$ and 5,202 , respectively) for a similar number of patients (3,250 and 3,004, respectively). Overall, 17,115 diagnosis-specific messages were displayed to clinicians in the intervention group during this period; 12,618 $(74 \%)$ of these messages were for diagnoses associated with medications in the 10 high-cost drug categories. In addition, 88 (70\%) of the daily messages sent to clinicians during the study period pertained to one of the drugs in the top 10 categories.

Table 2 summarizes the prescription costs for the 
intervention and control groups. After implementation of the CDSS, the mean cost per new prescription was $\$ 4.16$ lower (95\% CI, \$0.84-\$7.49, $P=.02$ ) in the intervention group. These new prescriptions were refilled an average of 1.3 times during 6 months of follow-up, producing an additional 7,470 claims in the intervention group and 6,900 claims in the control group. Including refills, the cost per prescription was $\$ 4.99$ lower $(95 \% \mathrm{CI}, \$ 1.49-\$ 8.48, P=.01)$ in the intervention group. The 6-month savings from new prescriptions and their refills are estimated to be $\$ 65,554$ (95\% CI, $\$ 19,574-\$ 111,402)$ or $\$ 3,450$ (95\% CI $\$ 1,030-\$ 5,863)$ per clinician. Overall, compared with baseline, prescription costs tended to increase in the control group, whereas they decreased in the intervention group.

Table 3 summarizes the changes in prescription costs for the 10 high-cost drug categories. Mean prescription costs during the study period were consistently lower in the intervention group compared with those in the control group, with significant between-group differences observed for all categories combined $(P=.03)$ and within the categories of antidepressants $(P=.02)$, gastroesophageal reflux disease medications $(P=.01)$, and antihypertension medications $(P=.01)$. Significant decreases from baseline costs were observed in the intervention group overall $(P=.01)$ and within the categories of antidepressants $(P=.002)$, asthma medications $(P$ $=.04)$, antihypertension medications $(P=.001)$, and headache medications $(P=.03)$. There was a significant net intervention effect within the category of headache medications $(\$ 47.49$ [95\% CI, \$11.51-\$83.47], P = .01) and clinically meaningful trends within the category of antidepressants (\$7.96 [95\% CI, -\$0.29-\$6.20], $P=.06)$ and all categories combined $(\$ 4.43[95 \%$ CI, $\$ 0.18-\$ 9.04], P=.06)$.

\section{DISCUSSION}

Providing information about the relative efficacy, safety, and cost of different therapeutic options during the electronic prescribing process had a significant impact on prescription costs. Prescription costs continued to increase in the control group, which is consistent with national drug expenditure trends. At the same time, prescription costs decreased in the intervention group. Overall, drug 
costs were decreased by approximately $11 \%$ in the group using the CDSS.

The CDSS used in this study displayed concise, credible information that was relevant to the clinical condition being treated, and it provided this information within the clinician's workflow. After a diagnosis was selected, prewritten prescriptions and evidencebased messages relevant to the chosen diagnosis were automatically displayed. We believe these attributes were critical to the success of the system. In other studies, computerized delivery of evidence-based guidelines had no impact when the information was not timely, relevant, and easy to access. ${ }^{9,10}$ Likewise, a computerized system with preventive care reminders was not effective when it required clinicians to choose to see the recommendations, but succeeded when the same system displayed prewritten orders that were easily implemented. ${ }^{11,12}$

A number of unique aspects of the study environment warrant discussion. The Affinity Health System is an integrated network with its own health plan and group of primary care and specialty physicians. Although the health system paid for the cost of the CDSS, these clinicians received no financial incentives to use the system or to modify their prescribing behavior. For logistical reasons, the intervention group consisted of clinicians from office sites where the system was first implemented. The sites were determined based on expressed clinician interest and convenience. It was not possible to randomize clinicians to intervention or control status.

Although the prescribing behavior was nearly identical between groups at baseline, it is possible that unobserved differences between groups could have introduced selection bias. Bias also could have been introduced by limiting the baseline analyses to new prescriptions only; however, a separate analysis of all prescription claims confirmed that the groups had remarkably similar prescribing behavior before implementation of the CDSS ( $\mathrm{n}=74,200$ prescriptions; mean cost per prescription was $\$ 46.29$ and $\$ 46.24$ in the intervention and control groups, respectively). The use of a control group that was closely matched at baseline and observed during the same period helped reduce the possibility that a changing patient mix, availability of new generic medications, or a change in the pharmacy benefit would influence the outcome.

Our results would be strengthened with longer follow-up; however, the study period had to be limited to 6 months to avoid cross-contamination of groups. New clinicians were being added to the system throughout the study period. By the end of the study period, clinicians in the control group were scheduled to begin using the system.
In conclusion, providing context-specific messages to clinicians in their workflow can shift prescribing decisions toward more evidence-based care and lower prescription costs. In this study, the savings associated with improved prescribing behavior easily offset the cost of the system.

To read or post commentaries in response to this article, see it online at http://www.annfammed.org/cgi/content/full/2/5/494.

Key words: Decision support systems, clinical; medical records systems, computerized; ambulatory care information systems; clinical pharmacy information systems; medical decision making, computer assisted; medical informatics applications; drug utilization; drug therapy, computer assisted

Submitted August 11, 2003; submitted, revised, March 15, 2004; accepted May 10, 2004.

This study was presented in part at the Academy of Managed Care Pharmacy's 15th Annual Meeting, April 11, 2003, Minneapolis, Minn.

Acknowledgments: The authors gratefully acknowledge Jennifer Resch for her assistance with data collection and Brian Waterman for his assistance with the statistical analysis.

\section{References}

1. McGettigan P, Golden J, Freyer J, Chan R, Feely J. Prescribers prefer people: the sources of information used by doctors for prescribing suggest that the medium is more important than the message. $\mathrm{Br}$ J Clin Pharmacol. 2001;51:184-189.

2. Bower AD, Burkett GL. Family physicians and generic drugs: a study of recognition, information sources, prescribing attitudes, and practices. J Fam Pract. 1987;24:612-616.

3. Caudill TS, Johnson MS, Rich EC, McKinney WP. Physicians, pharmaceutical sales representatives, and the cost of prescribing. Arch Fam Med. 1996;5:201-206.

4. Peay MY, Peay ER. The role of commercial sources in the adoption of a new drug. Soc Sci Med. 1988;26:1183-1189.

5. Hunt DL, Haynes RB, Hanna SE, Smith K. Effects of computer-based clinical decision support systems on clinician performance and patient outcomes. JAMA. 1998;280:1339-1346.

6. Kaushal R, Shojania KG, Bates DW. Effects of computerized physician order entry and clinical decision support systems on medication safety. Arch Intern Med. 2003;163:1409-1416.

7. Bates DW, Ebell M, Gotlieb E, et al. A proposal for electronic medical records in U.S. primary care. J Am Med Inform Assoc. 2003;10:1-10.

8. Murray DM. Design and Analysis of Group-Randomized Trials. New York, NY: Oxford University Press; 1998.

9. Eccles M, McColl E, Steen N, et al. Effect of computerized evidence based guidelines on management of asthma and angina in adults in primary care: cluster randomized controlled trial. BMJ. 2002; 325:941-947.

10. Rousseau N, McColl E, Newton J, Grimshaw J, Eccles M. Practice based, longitudinal, qualitative interview study of computerized evidence based guidelines in primary care. BMJ. 2003;326:314-321.

11. Overhage JM, Tierney WM, McDonald CJ. Computer reminders to implement preventive care guidelines for hospitalized patients. Arch Intern Med. 1996;156:1551-1556.

12. Dexter PR, Perkins S, Overhage JM, Maharry K, Kohler RB, McDonald CJ. A computerized reminder system to increase the use of preventive care for hospitalized patients. N Engl J Med. 2001;345:965-970. 